\title{
X-Ray Diffraction Texture Analysis of Uranium Alloy Fuel PLN-5527 R0
}

\author{
Douglas L Porter, Kevin R. Tolman
}

December 2018

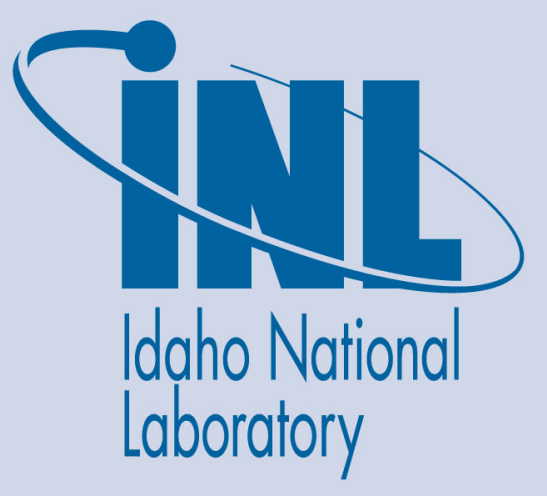

The INL is a U.S. Department of Energy National Laboratory operated by Battelle Energy Alliance 


\title{
X-Ray Diffraction Texture Analysis of Uranium Alloy Fuel PLN-5527 R0
}

\author{
Douglas L Porter, Kevin R. Tolman
}

December 2018

Idaho National Laboratory Idaho Falls, Idaho 83415

http://www.inl.gov

Prepared for the U.S. Department of Energy Office of Nuclear Energy Under DOE Idaho Operations Office Contract DE-AC07-05ID14517 


\section{Research and Development Test Control Plan}

\section{X-Ray Diffraction Texture Analysis of Uranium Alloy Fuel}

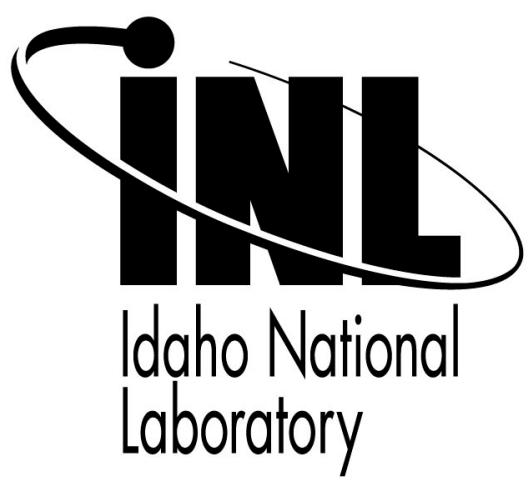

The INL is a U.S. Department of Energy National Laboratory operated by Battelle Energy Alliance. 


\section{DISCLAIMER}

Neither the U.S. Government nor any agency thereof, nor any of their employees, makes any warranty, expressed or implied, or assumes any legal liability or responsibility for the accuracy, completeness, or usefulness, of any information, apparatus, product, or process disclosed, or represents that its use would not infringe privately owned rights. References herein to any specific commercial product, process, or service by trade name, trade mark, manufacturer, or otherwise, does not necessarily constitute or imply its endorsement, recommendation, or favoring by the U.S. Government or any agency thereof. The views and opinions of authors expressed herein do not necessarily state or reflect those of the U.S. Government or any agency thereof. Being provided this document, directly or indirectly, shall not be construed to constitute a governmental export license or authorization.

\section{GENERATED INFORMATION - UNLIMITED RIGHTS}

This document contains, at least in part, Generated Information - Unlimited Rights arising under CRADA No. 13-CR-13 between TerraPower, LLC, and Battelle Energy Alliance, LLC. 


\section{Idaho National Laboratory}

X-RAY DIFFRACTION TEXTURE ANALYSIS OF URANIUM ALLOY FUEL

Identifier: $\quad$ PLN-5527

Revision: $\quad 0$

Effective Date: $01 / 15 / 2018 \quad$ Page: ii of $\mathbf{v}$

\begin{tabular}{|l|l|l|l|}
\hline Materials and Fuels Complex & Test Plan & USE TYPE: NA & eCR Number: 656233 \\
\hline
\end{tabular}

\section{REVISION LOG}

\begin{tabular}{|c|c|c|c|}
\hline Rev. & Date & Affected Pages & Revision Description \\
\hline 0 & $01 / 15 / 18$ & All & See eCR 656233. New Issue. \\
\hline & & & \\
\hline & & & \\
\hline & & & \\
\hline & & & \\
\hline & & & \\
\hline & & & \\
\hline & & & \\
\hline & & & \\
\hline & & & \\
\hline & & & \\
\hline & & & \\
\hline
\end{tabular}




\begin{tabular}{|c|lll|}
\hline X-RAY DIFFRACTION TEXTURE & Identifier: & PLN-5527 & \\
ANALYSIS OF URANIUM ALLOY FUEL & Revision: & 0 & \\
& Effective Date: & $01 / 15 / 2018$ & Page: iii of $\mathbf{v}$ \\
\hline
\end{tabular}

See eCR 656233

Kevin Tolman

Date

Principal Investigator

See eCR 656233

Doug Porter

Technical Lead

Date

See eCR 656233

Gregory Core

Date

Project Manager 


\begin{tabular}{|c|lll|}
\hline X-RAY DIFFRACTION TEXTURE & Identifier: & PLN-5527 & \\
ANALYSIS OF URANIUM ALLOY FUEL & Revision: & 0 & \\
& Effective Date: & $01 / 15 / 2018$ & Page: iv of v \\
\hline
\end{tabular}

\section{CONTENTS}

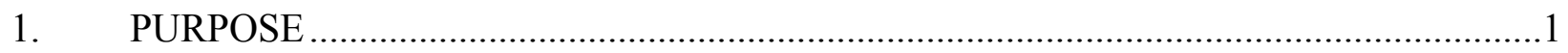

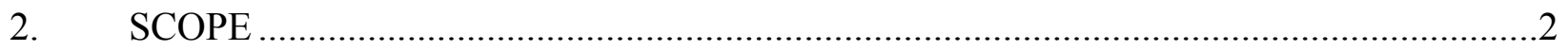

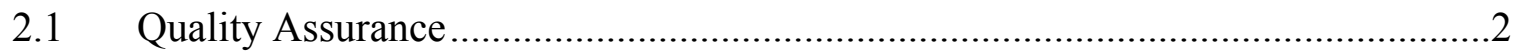

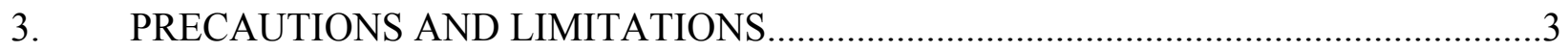

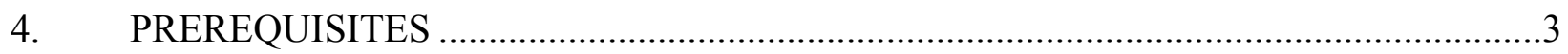

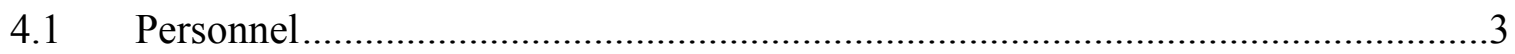

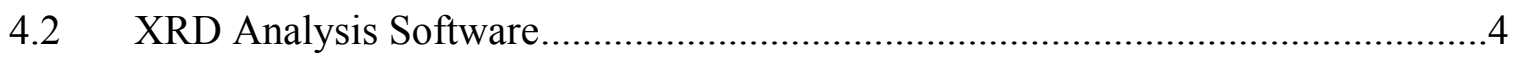

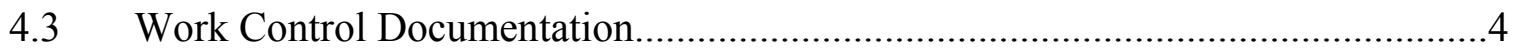

4.4 Instrumentation, Equipment, and Calibrations ……………………………….....

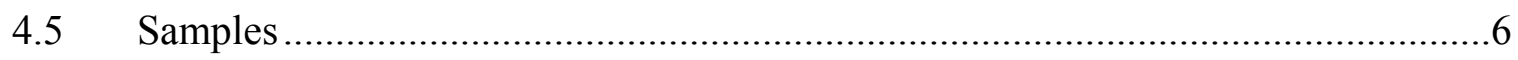

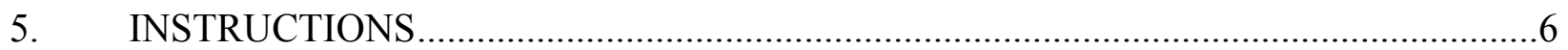

$5.1 \quad$ Sample Preparation Requirements ...................................................................

5.1.1 Sample Sectioning and Polishing ...........................................................

5.1.2 Sample Examination via X-ray Diffraction (XRD) ..................................

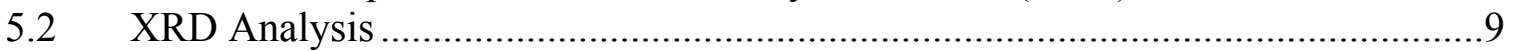

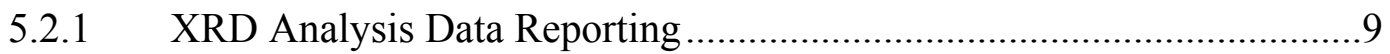

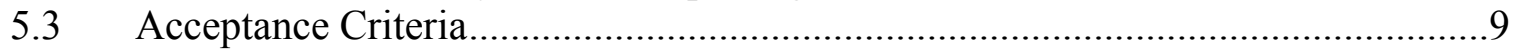

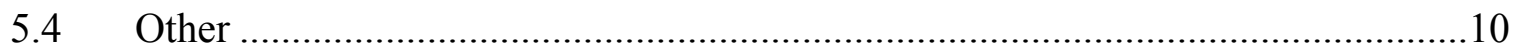

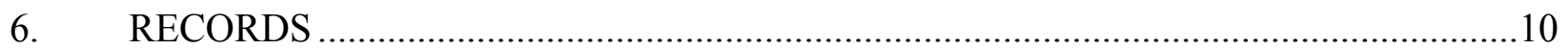

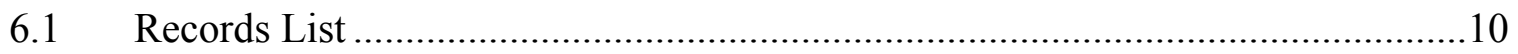

6.2 Laboratory Notebooks and Summary Sheets.......................................................11

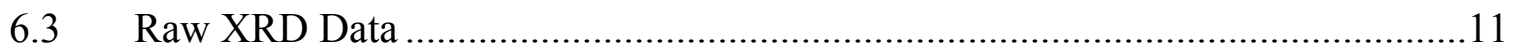

6.4 Final XRD Examination Technical Reports …………………………………....11

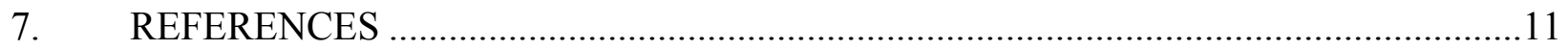




\begin{tabular}{|c|lll|}
\hline X-RAY DIFFRACTION TEXTURE & Identifier: & PLN-5527 & \\
ANALYSIS OF URANIUM ALLOY FUEL & Revision: & 0 & \\
Effective Date: & $01 / 15 / 2018$ & Page: v of v \\
\hline
\end{tabular}

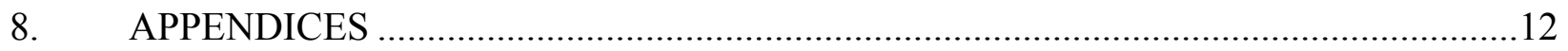

Appendix A — Assessing Texture in Archive and Retention Samples............................13

Appendix B - XRD Characterization Supporting Development and Fabrication of Type A, Type B, and Type C Fuel Pins/Slugs...............................................15

Appendix C — Sample Summary Sheet Example .....................................................16

Appendix D — XRD Evaluation Summary Sheet Example ...................................... 17

Appendix E — XRD Test Plan Data Flow ............................................................ 18 


\begin{tabular}{|c|lll|}
\hline X-RAY DIFFRACTION TEXTURE & Identifier: & PLN-5527 & \\
ANALYSIS OF URANIUM ALLOY FUEL & Revision: & 0 & \\
& Effective Date: & $01 / 15 / 2018$ & Page: 1 of $\mathbf{1 8}$ \\
\hline
\end{tabular}

\section{PURPOSE}

X-ray diffraction examinations and diffraction-data analysis will be carried out in order to characterize the metallographic texture of metallic fuel alloys.

These examinations will be performed on uranium alloy fuel slugs, for which the sectioning requirements are provided here, including sample preparation, X-ray diffraction (XRD) details, and data analysis. As-cast, cold/hot-worked, and heat treated uranium alloyed samples are also mentioned as they will be cut, polished, and prepared for XRD.

X-ray diffraction (XRD) is performed to identify the crystal structure (identification of phases), lattice parameters and distortions in the fuel due the fabrication and processing of uranium alloys. These parameters may include but are not limited to refined lattice constants and angles, atomic positions and symmetry, strain, crystallite size, and preferred orientation (i.e., texture). Texture measurements can be quantified and compared between uranium alloy samples (e.g., XRD data peak ratios, or some other timely and approved texture measuring method).

As part of fuel fabrication development activities, samples from cast billets and extruded materials may be scanned in order to verify maximum peak reflection intensities and fullwidth-at-half-maximum (i.e., peak shapes) of the starting alloy prior to processing (i.e., cold/hot-worked, heat treated, etc.). This work is currently planned to be done as part of work scope in SPP-16809. Other work, which includes examination of archive injection cast EBR-II U-10Zr materials and low alloy, AFC-4B and AFC-4D characterization samples will be done as part of CRADA 13-CR-13 work scope. FFTF archive samples may also be considered under the 13-CR-13 work scope.

Data collected under this plan will be used to characterize material attributes in fuel alloy samples (i.e., metallographic texture). This information will support on-going process development activities and provide a comparison-basis between current and historical samples (i.e., archive and retention samples previously manufactured).

Uranium alloy samples may be heat treated to reduce or eliminate texture in the fuel. The heat treating of these samples to reduce texture will be done as prescribed by a separate test plan.

This test plan was generated in accordance with MCP-1380, "Research and Development Test Control." 


\begin{tabular}{|c|lll|}
\hline X-RAY DIFFRACTION TEXTURE & Identifier: & PLN-5527 & \\
ANALYSIS OF URANIUM ALLOY FUEL & Revision: & 0 & \\
& Effective Date: & $01 / 15 / 2018$ & Page: 2 of $\mathbf{1 8}$ \\
\hline
\end{tabular}

\section{SCOPE}

This test plan describes XRD sample characterization for uranium alloys. This test plan includes preferred sample preparation information, characterization method, instrument parameters, calibration method, analysis software, data-acceptance requirements, documentation/reporting requirements. Texture measurements will be taken based on relative peak shapes (e.g., peak height, area, integrated intensity, etc.), relative to the individual XRD pattern.

Specific XRD assessments included in the scope of this test plan are listed in Appendices.

It is required that the sample preparation, X-ray diffraction data collection and data processing be sufficiently defined and controlled to facilitate the needed material/sample comparisons and effective process development. Further, the texture analysis methodology developed and applied here may in the future be implemented as an inspection technique for candidate irradiation test fuel slugs.

\subsection{Quality Assurance}

Quality Assurance measures and practices associated with this task plan are derived from PLN-4553, Quality Assurance Program Plan for TerraPower, Metallic Fuel and Materials Development and Testing."

The work associated with this test plan is designated as "Applied Research:"

- $\quad$ Applied Research. A process, the objective of which is to gain knowledge or understanding necessary for determining the means by which a recognized and specific need may be met.

The process may involve basic research in selecting the best approach in accomplishing the applied research. It is a proof of principle with more explicit objectives and warrants a set of milestones. This leads to the need for a records system that can protect patent rights by ensuring an orderly procedure for maintaining the necessary documentation. Source: ASME NQA-1-2008 / 1a-2009 Addenda.

As discussed in PLN-4553, Applied Research activities are broken down into two categories, those intended to support licensing and those that are not. The intention of this division is to apply the appropriate level of quality to activities based upon the intended end use of the results. This plan includes activities of both categories. Each activity and its associated end use category are discussed in Appendix A and Appendix B. The quality assurance applied to the execution of each activity is determined based upon the end use determination shown in the appendices and the requirements provided in PLN-4553. 


\begin{tabular}{|c|lll|}
\hline X-RAY DIFFRACTION TEXTURE & Identifier: & PLN-5527 & \\
ANALYSIS OF URANIUM ALLOY FUEL & Revision: & 0 & \\
& Effective Date: & $01 / 15 / 2018$ & Page: 3 of 18 \\
\hline
\end{tabular}

Upon completion of the testing and acceptance of data by the procedures outlined in Section 5.3, relevant data files, Activity Sheets, and Summary Sheets will be established as project records (See Section 6).

Calibration-check of the x-ray diffractometer using a certified National Institute of Standards and Technology (NIST) reference material will be used in order to validate proper operation of the diffractometer (see Section 4.4).

\section{PRECAUTIONS AND LIMITATIONS}

XRD patterns will be taken at the Idaho National Laboratory (INL) Irradiated Materials Characterization Laboratory (IMCL), and planning will be done using the required "Work-Control Authorization and Work Release" of that facility by which the XRD work will be conducted. All activities, at a minimum, shall be performed in accordance with LWP-21220, "Work Management." Further instruction on work scope execution is provided by this test plan.

The uranium alloy processing including heat treatments will be covered by a separate test plan. Sample storage and tracking requirements are covered by facility operating instructions and are not covered by this test plan.

Work with radioactive samples requires a Radiological Work Permit (RWP) and Heath Physics Technician (HPT) surveys.

Fissile Material Handler (FMH) training qualification is required for personnel handling samples designated as "Accountable Nuclear Material (NM)" at INL facilities.

\section{PREREQUISITES}

\subsection{Personnel}

The following individuals are the key personnel for the execution of this workscope.

- $\quad$ Project Manager (PM): Gregory Core

- $\quad$ Principle Researcher (PR), responsible for sample preparation: Brady Mackowiak

- $\quad$ XRD Instrument Scientist (XRD SME), responsible for sample XRD evaluations, development, and reporting: Kevin Tolman

Dr. Kevin R. Tolman graduated in 2016 with a Ph.D. in Materials Science \& Engineering at Boise State University. His course work and research focus was on materials structural characterization and structure-property relationships using diffraction techniques (i.e., X-ray, electron, and 


\begin{tabular}{|c|lll|}
\hline X-RAY DIFFRACTION TEXTURE & Identifier: & PLN-5527 & \\
ANALYSIS OF URANIUM ALLOY FUEL & Revision: & 0 & \\
& Effective Date: & $01 / 15 / 2018$ & Page: 4 of 18 \\
\hline
\end{tabular}

neutron diffraction) for developing processing-structure relationships for a class of electroceramics called perovskites. Dr. Tolman has experience with both LeBail and Rietveld refinements for both metallic and ceramic materials. In December 2016, Dr. Tolman was hired as an X-ray diffraction analyst at Idaho National Laboratory (INL). His research at INL focuses on analyzing the crystal structures via X-ray diffraction of nuclear reactor fuels and post-irradiated materials."

- Quality Engineer: Randall Allen

The Instrument Scientist responsible for this work must:

1. Be familiar with the sample requirements and data-acceptance requirements of this test plan.

2. Verify that the operators (Research Associates, R\&D Technicians) who perform the activities associated with sample sectioning meet the training requirements of the facility.

3. Be familiar with the physical operation of the equipment and their limits, including vendor-supplied operation, troubleshooting, and applicable calibration procedures.

The Principal Researcher (PR) responsible for sample preparation must:

1. Understand the program requirements of each of the samples being prepared, including final use, to determine sample acceptability.

2. Understand the characteristics of the fuel pins available for sectioning and the consequences of deviations from this test plan.

3. Verify that the operators (Research Associates, R\&D Technicians) who perform the activities associated with sample sectioning meet the training requirements of the facility.

\subsection{XRD Analysis Software}

Rietveld refinements will be accomplished by, but not limited to 2009 Bruker AXS TOPAS version 4.2. Other refinement software may include: GSAS, FULLPROF, or HighScore+.

\subsection{Work Control Documentation}

The work management process that is used to facilitate research and development (R\&D) is established in LWP-21220, Work Management. 


\begin{tabular}{|c|lll|}
\hline X-RAY DIFFRACTION TEXTURE & Identifier: & PLN-5527 & \\
ANALYSIS OF URANIUM ALLOY FUEL & Revision: & 0 & \\
& Effective Date: & $01 / 15 / 2018$ & Page: 5 of $\mathbf{1 8}$ \\
\hline
\end{tabular}

Three work control categories are established for R\&D activities, they are:

- Very low risk - no documentation required; work performed as Routine Activity Envelope (RAE)

- $\quad$ Low risk - work performed per Performer Controlled Activity (PCA) documentation. PCA documents are designated by LST-.

- $\quad$ Greater than low risk - work performed per Laboratory Instructions (LI) documentation. Lis are designated by \#\#\#\#-YY-Facility, or LI-\#\#\#.

Both PCAs and Lis will utilized for conducting work associated with this test plan.

Namely, for sample preparation and XRD analysis, the following work control documents are established:

- $\quad$ 1219-07-MFC, Sample Preparation in MFC Radiological Laboratories

- $\quad$ 1356-07-FASB, FASB General Laboratory Work

- 1222-07-FASB, Accutom 50 High Speed Saw

- $\quad$ LST-904, XRD Operation in IMCL

- $\quad$ 1730-13-IMCL, Sample Preparation Activities

- 1664-11-CESB_Uranium Machining in EFF/FASB

- 1212-07-FASB - Uranium and Uranium Alloy Cleaning.

\subsection{Instrumentation, Equipment, and Calibrations}

Equipment needed to perform scope must be in-service and available.

X-ray diffractometer calibration will be performed after diffractometer maintenance to ensure proper operation of the diffractometer. In addition, calibration of the diffractometer will be performed if the instrument has been used for another purpose or project during the execution of the scope in this test plan. Calibration will be accomplished using a certified NIST standard reference material (e.g., lanthanum hexaboride powder NIST SRM 660 certificate). For acceptable results from this calibration standard, the resulting $2 \theta$ value must be within 0.002 degrees. 


\begin{tabular}{|c|lll|}
\hline X-RAY DIFFRACTION TEXTURE & Identifier: & PLN-5527 & \\
ANALYSIS OF URANIUM ALLOY FUEL & Revision: & 0 & \\
& Effective Date: & $01 / 15 / 2018$ & Page: 6 of $\mathbf{1 8}$ \\
\hline
\end{tabular}

NOTE: Monthly system calibration-checks will be performed as well as prior-to-use if system configuration changes have been made by other users of the equipment. Instrument configuration changes include: sample stage change, system software revision, instrument maintenance. Instrument calibration checks will be documented via the Instrument Log book or a Laboratory Notebook.

All other equipment (balances, micrometers, etc.) must be calibrated in accordance with the procedures referenced in PLN-4553, as applicable.

Potential sources of uncertainty and error in the measurement shall be identified, documented, and minimized as appropriate.

\subsection{Samples}

Alloy samples to support work scope are acceptable per given PR direction and are physically available for examination.

Electro-polishing of the samples may be required. If electro-polishing is required for samples of uranium alloyed with zirconium then the electro-polishing activity must be evaluated for safety by a Subject Matter Expert (SME) in that volatile compounds may form upon acid dissolution of these alloys. Such evaluations are addressed in LI 1219-07-MFC, Sample Preparation in MFC Radiological Laboratories. INL FRM 1019, "Sample Request Form" is utilized to evaluate and document any special requirements needed for preparation of specific types of radiological samples. Chemical cleaning of $\mathrm{U}-\mathrm{Zr}$ alloys is also addressed in LI 1212-07-FASB - Uranium and Uranium Alloy Cleaning.

\section{INSTRUCTIONS}

Alloy composition, processing history and heat treatment(s), sample origin-location and sample-orientation, and sample preparation details are important information needed to support the XRD evaluation to be performed.

For each sample submitted for XRD evaluation, the following information, as applicable, will be provided by the by the "PR responsible for sample preparation" to the "XRD SME responsible for XRD evaluations" and the PM.

- $\quad$ Sample ID

- Work Scope Element (CRADA 13-CR-13, SPP-16809, etc.)

- $\quad$ Alloy composition

- $\quad$ Processing history (e.g., extrusion and/or casting parameters) 


\begin{tabular}{|c|lll|}
\hline X-RAY DIFFRACTION TEXTURE & Identifier: & PLN-5527 & \\
ANALYSIS OF URANIUM ALLOY FUEL & Revision: & 0 & \\
& Effective Date: & $01 / 15 / 2018$ & Page: 7 of $\mathbf{1 8}$ \\
\hline
\end{tabular}

- $\quad$ Secondary processing information (e.g., drawing, heat treatment)

- $\quad$ Sample preparation info.(sample map/section diagram, grinding/polished summary)

- Sample orientation relative to manufacturing process.

The communication of the above listed information will be facilitated via the use of a Sample Summary Sheet; Example provided in Appendix C.

\subsection{Sample Preparation Requirements}

The metal slug, prior to sectioning, must be non-destructively marked such that, after sectioning, each segment of the slug can still be identified for orientation (top/bottom, etc.) and location. This is normally done with a black permanent marker.

All sectioning shall be documented and recorded in the associated Laboratory Notebook or Activity Sheet. Deviations from the sectioning instructions must be documented and discussed with the PR prior to proceeding. The dimensions, processing history including any casting, cold/hot working, and/or heat treatments will be documented and identified, with the appropriate sample identification number, in the Notebook or Activity Sheet.

\subsubsection{Sample Sectioning and Polishing}

Sectioning shall be performed using a saw rather than shearing to prevent undue plastic deformation in the sample. After sectioning each sample, the samples must be kept separate by placement into appropriate individual sample holders/containers with unique identification. Sample dimensions for XRD examination(s) should be less than $25 \times 25 \times 20 \mathrm{~mm}$; however, preferred unmounted sample height is $4 \mathrm{~mm}(+/-1 \mathrm{~mm})$, with a diameter of $6.5 \mathrm{~mm}(+/-3.5 \mathrm{~mm})$.

The samples shall be temporarily mounted for polishing, then removed from mount for XRD examination. Each mounted sample may be individually labeled and marked with the unique identification and orientation of the sample. Each sample is then to be ground and polished to a final finish that is acceptable to perform XRD examination (i.e., down to $1 \mu \mathrm{m}$ ). Sample may be adhered to mount with crystal-bond for grinding and polishing steps to maintain fuel integrity. Polishing typically involves grinding the sample through 1200 grit and a polish of 6,3 , and $1 \mu \mathrm{m}$ diamond suspensions. Samples may have this process repeated, as necessary, to locate features of interest or to get to a specific location within the sample. 


\begin{tabular}{|c|lll|}
\hline X-RAY DIFFRACTION TEXTURE & Identifier: & PLN-5527 & \\
ANALYSIS OF URANIUM ALLOY FUEL & Revision: & 0 & \\
& Effective Date: & $01 / 15 / 2018$ & Page: 8 of $\mathbf{1 8}$ \\
\hline
\end{tabular}

Note that electro-polishing may be required. If electro-polishing is required for samples of uranium alloyed with zirconium then the electropolishing activity must be evaluated for safety by a subject matter expert (SME) in that volatile compounds may form upon acid dissolution of these alloys.

After polishing, the samples shall then be removed from their temporary mount, smearably clean, and transferred to the appropriate laboratory (e.g., IMCL) for XRD examination(s) and analysis. Orientation of the samples must be maintained after sectioning with the sample's associated origin location.

\subsubsection{Sample Examination via X-ray Diffraction (XRD)}

Once the unmounted sample(s) have been transferred, the unmounted sample(s) shall be smearably cleaned (surveyed by HPT), placed in a suitable XRD sample holder, and placed in the diffractometer for examination. The XRD SME will determine the most appropriate sample loading options. Suitable x-ray diffractometers include, but are not limited to the IMCL PANalytical Empyrean, IMCL Bruker D8 Discover. For instance, the PANalytical Empyrean diffractometer system parameters may have, but not limited to the following conditions:

- $\quad$ Automatic slit system and sample spinning

- $\quad$ Range $10^{\circ} \geq 2 \theta \geq 120^{\circ}$

- Increment $0.02^{\circ}$

- Incident Beam

- Solar 0.04 radians

- Radius $24 \mathrm{~cm}$

- Take off angle $6^{\circ}$

- Distance to sample $14 \mathrm{~cm}$

- Irradiated length $10 \mathrm{~mm}$

- Mask No.10 (6 mm × $14 \mathrm{~mm})$

- Fixed slit $2^{\circ}(4 \mathrm{~mm} \times 30 \mathrm{~mm})$ 


\begin{tabular}{|c|lll|}
\hline X-RAY DIFFRACTION TEXTURE & Identifier: & PLN-5527 & \\
ANALYSIS OF URANIUM ALLOY FUEL & Revision: & 0 & \\
& Effective Date: & $01 / 15 / 2018$ & Page: 9 of $\mathbf{1 8}$ \\
\hline
\end{tabular}

- Diffracted Beam

- Solar 0.04 radians

- Radius $24 \mathrm{~cm}$

- Observed length $10 \mathrm{~mm}$.

The XRD SME will ensure proper sample loading, system alignment, and diffractometer conditions.

\subsection{XRD Analysis}

After the XRD scan has completed, the XRD data will be analyzed for, but not limited to:

- $\quad$ Lattice parameters

- $\quad$ Texture measurements.

Additional scans may be collected as needed by the XRD SME to document any other features of interest. All XRD data should be saved using a retrievable file format and labeled such that the location on each scan is easily discerned.

\subsubsection{XRD Analysis Data Reporting}

The following information will be provided by the by the XRD SME to the Project Manager (PM) for each sample evaluated.

- $\quad$ Sample information, as detailed above in Section 5 introduction (e.g., sample ID, processing history, etc.)

- $\quad$ XRD evaluation summary (what was done)

- $\quad$ Results Summary (as applicable), may be deferred to interim or final report.

The communication of the above listed information will be facilitated via the use of XRD Evaluation Summary Sheet; Example provided in Appendix D.

\subsection{Acceptance Criteria}

$\mathrm{XRD}$ data recorded according to this plan will be recorded, reviewed, and reported by the XRD SME. This review shall be conducted to ensure that all test requirements have been satisfied and that any data anomalies have been addressed. As the purpose of this test plan is not to confirm acceptability of fuel 


\begin{tabular}{|c|lll|}
\hline X-RAY DIFFRACTION TEXTURE & Identifier: & PLN-5527 & \\
ANALYSIS OF URANIUM ALLOY FUEL & Revision: & 0 & \\
& Effective Date: & $01 / 15 / 2018$ & Page: 10 of 18 \\
\hline
\end{tabular}

specimens but rather to investigate the characteristics of fuel specimens and proposed XRD examination methodology, acceptance criteria for the XRD analyses results do not exist.

All resulting data shall be validated by a peer review prior to their formal release. Furthermore, data intended to be used for a licensing must be independently reviewed prior to release. An INL Quality Engineer must also review this latter form of data for acceptability.

Data review must be documented using the INL eCR process, engineering review process (e.g., LWP-10200, "Engineering Calculations and Analysis Report"), STIMS process, or other mechanisms as appropriate for the type of documentation generated. The final, approved document with evidence of a review incorporating the elements listed above must be entered into the EDMS or alternative means, as established in TerraPower Agreements (i.e., Statement of Works).

If the XRD data does not meet the needs of the program because of a non-compliance with this test plan, the non-compliance must be addressed by the assigned technical lead, i.e. Doug Porter, or PM, i.e. Greg Core.

\subsection{Other}

The origin-location of all samples taken must be recorded.

The location, orientation, and identification of each sample must be recorded such that each sample can be associated with a specific source.

Sample's processing history and heat treatments must be individually identifiable and stored for transfer to the applicable laboratory for XRD examination.

\section{RECORDS}

\subsection{Records List}

- $\quad$ Sample and Sample Preparation

- Sample Summary Sheet (see Appendix C).

XRD

- Data Collection and Analysis

- XRD Evaluation Summary Sheet (see Appendix D). 


\begin{tabular}{|c|lll|}
\hline X-RAY DIFFRACTION TEXTURE & Identifier: & PLN-5527 & \\
ANALYSIS OF URANIUM ALLOY FUEL & Revision: & 0 & \\
& Effective Date: & $01 / 15 / 2018$ & Page: 11 of $\mathbf{1 8}$ \\
\hline
\end{tabular}

- $\quad$ Final XRD examination report(s) per requirements shown in the appendices of this test plan.

\subsection{Laboratory Notebooks and Summary Sheets}

Laboratory notebooks are permissible for use in data collection per PLN-4553 under the INL procedure MCP-2875, "Proper Use and Maintenance of Laboratory Notebooks." All summary sheets generated in executing the workscope defined in this test plan shall be considered separate records and handled as such.

\subsection{Raw XRD Data}

A copy of all relevant XRD data collection and analysis files will be logged as "project records", and placed on a controlled server, i.e. working files location and/or archive files location, as applicable.

\subsection{Final XRD Examination Technical Reports}

Final technical reports detailing the results of the XRD examinations shall be generated. These reports shall include the data acceptability review discussed in Section 5.3. All applicable summary sheets shall be included as an appendix to each report.

\section{REFERENCES}

PLN-4553, Quality Assurance Program Plan for TerraPower, Metallic Fuel, and Materials Development and Testing.

LWP-21220, Work Management.

LWP-10200, Engineering Calculations and Analysis Report.

MCP-1380, Research and Development Test Control.

MCP-2875, Proper Use and Maintenance of Laboratory Notebooks.

1219-07-MFC, Sample Preparation in MFC Radiological Laboratories.

1356-07-FASB, FASB General Laboratory Work.

1222-07-FASB, Accutom 50 High Speed Saw.

LST-904, XRD Operation in IMCL.

1730-13-IMCL, Sample Preparation Activities

1664-11-CESB_Uranium Machining in EFF/FASB. 


\begin{tabular}{|c|lll|}
\hline X-RAY DIFFRACTION TEXTURE & Identifier: & PLN-5527 & \\
ANALYSIS OF URANIUM ALLOY FUEL & Revision: & 0 & \\
& Effective Date: & $01 / 15 / 2018$ & Page: 12 of 18 \\
\hline
\end{tabular}

1212-07-FASB - Uranium and Uranium Alloy Cleaning.

FRM 1019, Sample Request Form.

\section{APPENDICES}

Appendix A: Assessing Texture in Archive and Retention Samples

Appendix B: XRD Characterization Supporting Development and Fabrication of Type A, Type B, and Type C Fuel Pins/Slugs

Appendix C: Sample Summary Sheet Example

Appendix D: XRD Evaluation Summary Sheet Example

Appendix E: XRD Test Plan Data Flow 


\begin{tabular}{|c|lll|}
\hline X-RAY DIFFRACTION TEXTURE & Identifier: & PLN-5527 & \\
ANALYSIS OF URANIUM ALLOY FUEL & Revision: & 0 & \\
& Effective Date: & $01 / 15 / 2018$ & Page: 13 of $\mathbf{1 8}$ \\
\hline
\end{tabular}

Appendix A

Assessing Texture in Archive and Retention Samples

Project: CRADA 13-CR-13

Task 1: Assessing Texture in Thirty Archive EBR-II U-10Zr Fuel Slug Samples

Activity Type (per PLN-4553): Applied Research

Data End Use Determination: For use in licensing

Samples ( $\sim 0.25$-inches long) had been cropped from the ends of fifteen EBR-II driver fuel slugs, five each from batches of MK-III, MK-IV, and MK-IIC fuel pins where the fuel had been recovered when stripped from the pins for reclamation. Each was sawed in half to eliminate the potential effects of cold working caused by cleaving/shearing the samples from the ends of the fuel slugs; the saw-cut surfaces could be used for the examination. One half of the cut sample had been mounted in epoxy and examined by XRD. This work will use the other halves of the samples, unmounted.

The samples will be scanned using the methods outlined above, and the results analyzed to determine if there is any evidence of texture in the samples.

There was also an examination of the outer edge of the fuel slug cross-section, formerly by SEM, to determine if there was a presence of a 'rind' (a layer composed of $\mathrm{Zr}$ silicide and $\mathrm{Zr}$ carbide). In this case optical metallography will be used to again identify which samples have a 'rind' for all samples. Upon examination of the initial results of this XRD testing, and the optical metallography for evidence of 'rind', as mentioned above, a subset will be scanned using a polished surface orthogonal to the original transverse cross section.

FFTF archive fuel samples may also be considered under this work scope.

Deliverable: Technical report for XRD of thirty EBR-II legacy fuel slug cross-section samples

Task 2: Assessing Texture in ATR AFC-4B and AFC-4D Experiment Retention Samples Activity Type (per PLN-4553): Applied Research

Data End Use Determination: For use in licensing

Task 2 entails the texture characterization via X-Ray Diffraction (XRD) of enriched fuel slug samples that were retained from the Sponsor's AFC-4B and AFC-4D fuel pin experiments that were fabricated for irradiation in the Advanced Test Reactor (ATR). There are thirteen samples, five for AFC-4B and eight for AFC-4D, available in archive as marked for XRD characterization. This test matrix will perform XRD examination on at least eight of them, four from AFC-4B and four from AFC-4D, those from 4B being from rodlets R-1, R-2, R-3, and R-4. The ones from AFC-4D will be randomly chosen from one of two (from segment A or from 


\begin{tabular}{|c|lll|}
\hline X-RAY DIFFRACTION TEXTURE & Identifier: & PLN-5527 & \\
ANALYSIS OF URANIUM ALLOY FUEL & Revision: & 0 & \\
& Effective Date: & $01 / 15 / 2018$ & Page: 14 of 18 \\
\hline
\end{tabular}

segment B) available from each of AFC-4D rodlets R-1, R-2, R-3, and R-4. All samples will receive a final electropolish before the XRD scan to remove any worked metal on their asmechanically-polished surface.

Upon examination of the initial results of this testing, a subset will be scanned using a polished surface orthogonal to the original transverse cross section.

Deliverable: Technical reports for XRD of ATR AFC-4B samples R1 through R4 and AFC-4D $\mathrm{R} 1$ through $\mathrm{R} 4$ (choose segment $\mathrm{A}$ or $\mathrm{B}$ of each) for eight samples total experiment retention samples. 


\begin{tabular}{|c|lll|}
\hline X-RAY DIFFRACTION TEXTURE & Identifier: & PLN-5527 & \\
ANALYSIS OF URANIUM ALLOY FUEL & Revision: & 0 & \\
& Effective Date: & $01 / 15 / 2018$ & Page: 15 of $\mathbf{1 8}$ \\
\hline
\end{tabular}

\section{Appendix B}

\section{XRD Characterization Supporting Development and Fabrication of Type A, Type B, and Type C Fuel Pins/Slugs}

\section{Project: SPP-16809}

Activity Type (per PLN-4553): Applied Research

Data End Use Determination: Not for use in licensing

Texture characterization via X-Ray Diffraction (XRD) of the baseline fuel microstructure before heat-treating, at intermediate processing points, and after the full heat treatment. Supporting development of analytical techniques to conduct this task.

Additional specific tasks to develop heat treatment/XRD techniques include but are not limited to the following:

- $\quad$ XRD analysis of up to three (3) as-cast Type A billets (transverse and longitudinal orientation, multiple samples per billet possible). As-cast billets are expected to represent relatively non-oriented microstructure and will help to form a baseline comparison for new fabrication methods.

\section{Deliverables:}

- $\quad$ TerraPower Type A Fuel Heat Treatment and XRD Development - Interim Report

- $\quad$ TerraPower Type A Fuel Heat Treatment and XRD Development - Final Report. 
Idaho National Laboratory

\begin{tabular}{|c|lll|}
\hline X-RAY DIFFRACTION TEXTURE & Identifier: & PLN-5527 & \\
ANALYSIS OF URANIUM ALLOY FUEL & Revision: & 0 & \\
& Effective Date: & $01 / 15 / 2018$ & Page: 16 of $\mathbf{1 8}$ \\
\hline
\end{tabular}

Appendix C

Sample Summary Sheet Example

TerraPower: XRD Sample Handoff Sheet

\begin{tabular}{l} 
Prepared by: $\underline{\text { Brady Mackowiak }}$ \\
Test Plan: $\underline{\text { PLN-5527,Rev 0,X-Ray Diffraction Texture Analysis of Uranium Alloy Fuel" }}$ \\
Appendix:_, Appendix Title: \\
Task \#: $\quad$ Task Title: \\
Activity Type: Applied Research \\
Data End Use Determination: For use in licensing \\
\hline I. Sample Information: \\
Sample(s) Identifier(s): \\
\hline II. Process History \\
Description:: \\
\hline Alloy DU10Zr: billet \#, Castingrun\# \\
Extrusion: Diameter, ID \\
Post Extrusion Heat Treat \#, Drawing\#, etc:
\end{tabular}

File(s)/Location:

III. Sample Preparation:

Description:

Sample Map: File name of sample map: $\square$ File(s)/Location

Geometry: Transverse cross section

Sectioning: High Speed or Low Speed saw

Grinding: $\quad$ Steps or recipe

Polishing: $\quad$ Steps or recipe ID

File(s)/Location:

IV. Other:

Comments issues associated with sample preparation:

File(s)/Location:

\begin{tabular}{|l|l|c|}
\hline V. Signature & Signature & Date \\
\hline Principle Researcher: & & \\
\hline
\end{tabular}




\begin{tabular}{|c|lll|}
\hline X-RAY DIFFRACTION TEXTURE & Identifier: & PLN-5527 & \\
ANALYSIS OF URANIUM ALLOY FUEL & Revision: & 0 & \\
& Effective Date: & $01 / 15 / 2018$ & Page: 17 of 18 \\
\hline
\end{tabular}

Appendix D

\section{XRD Evaluation Summary Sheet Example}

\section{TerraPower: XRD Evaluation Summary Sheet}

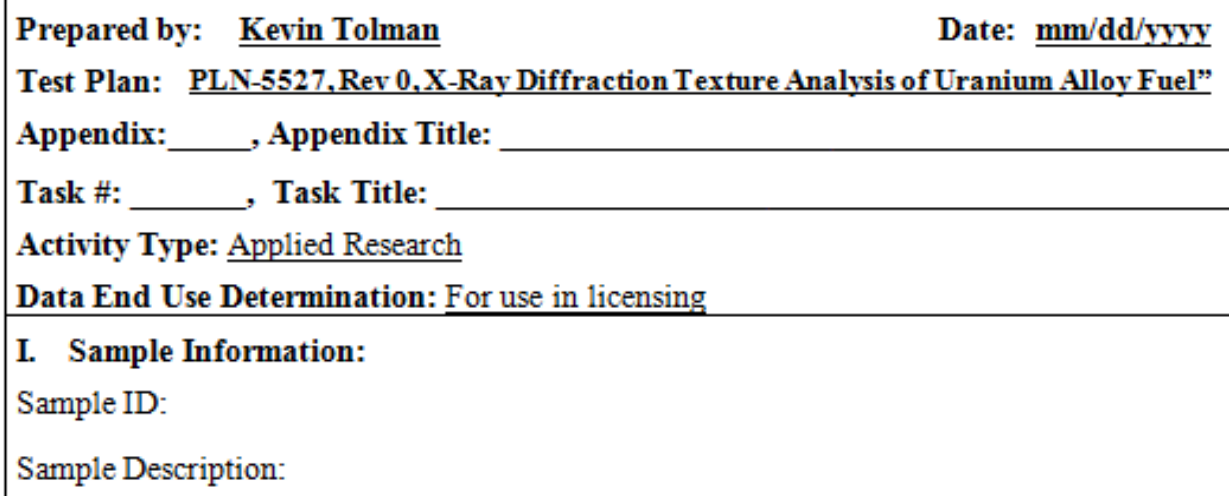

IV. Data and Analysis Files: Names and Location

\begin{tabular}{|l|l|l|}
\hline V. Signature & Signature & Date \\
\hline XRD SME: Kevin Tolman & & \\
\hline
\end{tabular}


Idaho National Laboratory

\begin{tabular}{|c|lll|}
\hline X-RAY DIFFRACTION TEXTURE & Identifier: & PLN-5527 & \\
ANALYSIS OF URANIUM ALLOY FUEL & Revision: & 0 & \\
& Effective Date: & $01 / 15 / 2018$ & Page: 18 of $\mathbf{1 8}$ \\
\hline
\end{tabular}

Appendix E

XRD Test Plan Data Flow

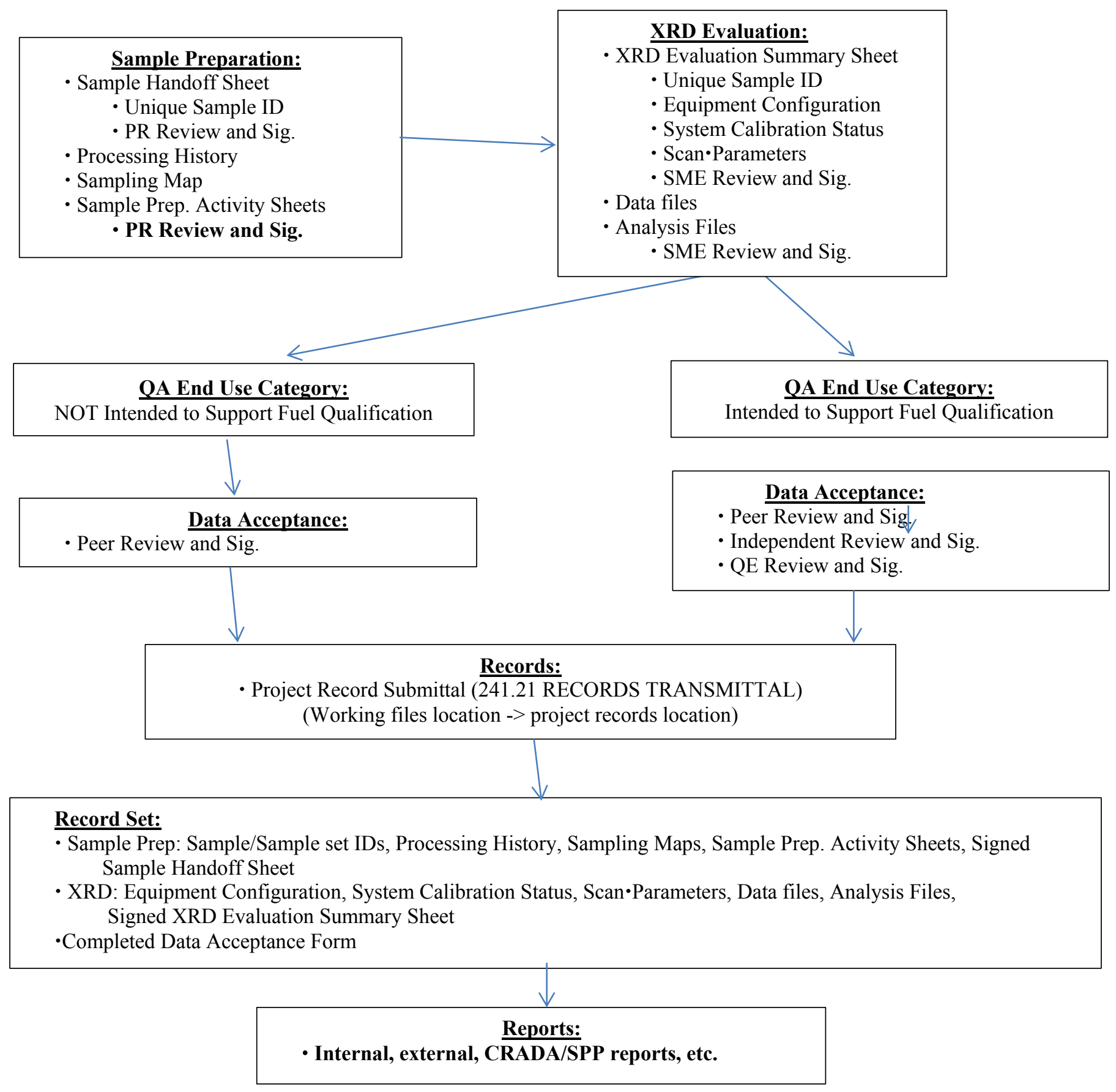

